\title{
Prevalence of Pulmonary Tuberculosis among the Elderly- An Observation from a Rural Province of Thailand
}

\author{
Pathum Sookaromdee ${ }^{1 *}$ and Viroj Wiwanitkit ${ }^{2}$ \\ 'TWS Medical Center, Bangkok, Thailand \\ ${ }^{2}$ Hainan Medical University, Haikou, China \& Dr. DY Patil University, Pune, India
}

\begin{abstract}
Tuberculosis is an important clinical problem worldwide in many countries in Asia. A high incidence of tuberculosis exists in Indochina. Some specific populations including the elderly, have a higher probability of getting infected. The aim of this study was to determine the prevalence of tuberculosis among elderly population in rural district of Thailand, a tropical country in Indochina. According to the study, all 22,033 Thai elderly in this area were screened for tuberculosis. Of these cases, there were 39 infected cases (prevalence rate $=0.18 \%, 95 \% \mathrm{Cl}: 0.13 \%-0.24 \%)$. In conclusion, tuberculosis is common among Thai elderly in this setting.
\end{abstract}

Keywords: Tuberculosis, elderly, Thailand.

\section{INTRODUCTION}

Tuberculosis is a chronic infection with a slow progressive course of disease. This mycobacterial infection can result in chronic illness and may result in death. At present, tuberculosis infection can be prevalent in many countries, leading to the consideration that tuberculosis is a global public health problem. Globally, there are more than 1 million patients with tuberculosis and the disease is also commonly seen along with HIV infection $[1,2]$. The disease usually occurs in the communities with poor sanitation. Developing countries in Asia usually have a higher rate of tuberculosis. In Asia, tuberculosis is an important regional public health problem. An estimated 3.4 million new cases of tuberculosis occur annually in this region, predominantly in India, Myanmar, Thailand, Bangladesh and Indonesia [3]. In addition to overt infection, latent infection is also common. Houben and Dodd noted that approximately 1.7 billion individuals were latently infected with tuberculosis [3].

Antituberculosis drugs are the main gold standard for treatment, however, a long term drug treatment for effective case management is required. At present, there are many problems regarding the tuberculosis treatment such as drug resistance, which already exists in many countries [4]. At present, tuberculosis is still endemic in many regions of the world. In Indochina, a tropical region, there are millions infected patients with tuberculosis [4, 5]. Although the antituberculosis treatment is available in this area, the success of tuberculosis management is still not achieved [1]. Because the treatment requires a long period, some patients may end up being lost to follow up from the treatment program. In fact, in Indochina, there are several problematic local endemic tropical diseases, in addition to tuberculosis [5]. The active case search is

\footnotetext{
*Corresponding Author: Pathum Sookaromdee, TWS Medical Center, Bangkok, Thailand;Email: pathumsook@gmail.com

Received: February 21, 2020; Revised: April 03, 2020; Accepted: April 10, 2020

DOI: https://doi.org/10.37184/lnjpc.2707-3521.1.17
}

another important attempt for early case detection. The screening is applied for some specific risk populations. Clinically, some specific populations have a higher risk of developing infection. The elderly are a group that have higher risk for developing tuberculosis. In the elderly, due to impaired normal physiological function, tuberculosis might easily occur [6]. The clinical spectrum of tuberculosis among the elderly has a wide range from subclinical to severe manifestation [6]. Due to impaired physiological status, the outcome of infection is poorer in the elderly than to the younger age group. The elderly also have an increased risk of side effects resulting from antituberuclosis medication [6]. In developing countries, tuberculosis is still an important public health problem [7]. The annual risk of tuberculosis is estimated at $1.4 \%$, with approximately 100,000 new cases annually [8, 9]. In the present study, the aim was to determine the prevalence of tuberculosis among elderly population in rural district of Thailand, a tropical country in Indochina.

\section{MATERIALS AND METHODS}

The current study is a secondary analysis of tuberculosis screening data collected in 2019. The primary data source is a public primary data that was recorded in a screening program which was conducted according to local public health policies for tuberculosis screening and provided by Lampang Provincial Health Office (www.lpho. go.th) which is freely publically available on Lampang Provincial Health Office website (http://www.Ipho. go.th/main/wp-content/plugins/download-attachments/ includes/download. .php?id=nBfue-I5HBq0PYCsIzWi06rngtwlCE-BFo7bYTq2rQ). Focusing on the screening program, it was performed during the year 2019, from January to December, by local community healthcare worker teams (physicians, nurses and community public health workers). The focused area was a rural province namely Lampang province of Thailand, a rural province in northern region of Thailand near Myanmar and Laos. 
In this study area, the active screening includes use of Chest X-ray, sputum AFB and gene X-pert test for all cases. The aim is to screen for pulmonary tuberculosis. According to the primary active screening program, the elderly who have addiction of smoking or narcotic drug history and presence of cancer were not screened.

The data on detection rate of tuberculosis among local Thai elderly was collected based on direct extraction on primary data then summarized in terms of frequency and percentage with $95 \%$ confidence interval. Chisquare test was applied to compare variables among TB positive and TB negative patients. $P$-value $<0.05$ was taken as statistically significant. Analysis was performed on SPSS (version 11.5).

\section{RESULTS}

According to the study, all 22,033 Thai elderly $(10,759$ males, $48.83 \%$; 11,274 females, $51.17 \%$ ) in this area were screened for tuberculosis. Of these, there were 39 infected cases (prevalence rate $=0.18 \%, 95 \% \mathrm{Cl}$ : $0.12 \%-0.23 \%$ ). Among 39 infected cases, most of them were of the age group $60-69$ years $(n=24,0.11 \%)$ followed by cases in age group of $70-79$ years $(n=10$, $0.05 \%)$ and only $5(0.02 \%)$ cases were observed in age group of 80 years and above. Regarding sex, 19(0.09\%) and $20(0.09 \%)$ cases were detected among males and females respectively. Classified by disabilities, tuberculosis infections were detected in 15(0.115\%) of 2,985 of elderly with disability (bed ridden and handicap) and $24(0.126 \%$ ) of 19,048 of elderly without disability, respectively. The elderly with disabilities had comparatively higher prevalence of tuberculosis infection $(p<0.001)$ (Table 1).

Table 1: Tuberculosis among Thai elderly classified by sex and age groups.

\begin{tabular}{|c|c|c|c|}
\hline- & $\begin{array}{c}\text { TB Positive } \\
\mathrm{n}(\%)\end{array}$ & $\begin{array}{c}\text { TB Negative } \\
\mathbf{n}(\%)\end{array}$ & $\begin{array}{c}\text { Chi-square } \\
\text { p-value }\end{array}$ \\
\hline \multicolumn{4}{|l|}{ Age (in years) } \\
\hline $60-69$ & $24(0.11 \%)$ & $13,245(60.22 \%)$ & \multirow{3}{*}{0.956} \\
\hline $70-79$ & $10(0.05 \%)$ & $5,559(25.23 \%)$ & \\
\hline 80 and above & $5(0.02 \%)$ & $3,190(14.48 \%)$ & \\
\hline \multicolumn{4}{|l|}{ Gender } \\
\hline Male & $19(0.09 \%)$ & $10740(48.75 \%)$ & \multirow{2}{*}{0.989} \\
\hline Female & $20(0.09 \%)$ & $11,254(51.08 \%)$ & \\
\hline \multicolumn{4}{|c|}{ Physical Disability Status } \\
\hline Disabled & $15(0.115 \%)$ & $2,970(99.885 \%)$ & $<0.001^{*}$ \\
\hline Not disabled & $24(0.126 \%)$ & $19,024(99.874 \%)$ & \\
\hline
\end{tabular}

*Significant, cut-off $p$-value $=0.05$.

** disability includes bed ridden and handicap

\section{DISCUSSION}

Basically, the standard management of tuberculosis is antituberculosis medication. An incomplete or improper drug treatment program is considered a failure and it can result in drug resistance of the Mycobacterium pathogen
[10-12]. Therefore, it is usually indicated for early and complete drug treatment of the patient. However, early management should be accompanied with early diagnosis. Therefore, active case search by screening for tuberculosis among risk population is required. As noted by Yasri and Wiwanitkit, successful control of tuberculosis among risk populations in Indochina is still reached and it requires improvement of present system for tuberculosis disease searching diagnosis and therapy [12].

In the present report, the authors focused on determining the prevalence of tuberculosis among Thai elderly in a rural province of Thailand, which was considerably high $(1.8 \%)$. The findings are similar to a reported prevalence in a recent study from China $(180.92 / 100,000)$ [13]. The prevalence in our setting is significantly higher than a reported prevalence in USA $(2.8 / 100,000)$ ) (data from US CBC, publically available on https://www.cdc.gov/tb/ education/ssmodules/pdfs/Module2.pdf).

Also, there is an extremely high rate among those with disability. This can confirm the fact that the elderly, especially those with disability, are a high risk group for developing tuberculosis infection [14].

Finally, some limitations of the present work were also noted. The observed rate in the present report reflects mainly on pulmonary tuberculosis. The in depth study on extrapulmonary tuberculosis was not done in the primary tuberculosis screening. Due to the high incidence of tuberculosis, modified screening to cover extrapulmonary tuberculosis is suggested for modification of local public health policies for tuberculosis control. In addition, some socio-demographic variables such as marital status and educational status are not available for analysis. There is also a lack of data on the common metabolic syndrome (diabetes, mellitus and dyslipidemia) among the screened elderly. Such limitations are inbuilt in secondary data. It is suggested that primary data are collected in order to control for several confounders that could not be addressed in the study.

\section{CONCLUSION}

The active screening showed a high incidence of tuberculosis among the local geriatric population. Active pulmonary tuberculosis management among the elderly in this area is important.

\section{CONFLICT OF INTEREST}

The authors declare no conflict of interest.

\section{ACKNOWLEDGEMENTS}

The authors acknowledge the public health team who collect and prepare primary public available data.

\section{REFERENCES}

1. Glaziou P, Floyd K, Raviglione MC. Global epidemiology of tuberculosis. Semin Respir Crit Care Med 2018; 39: 271-85. 
2. Floyd K, Glaziou P, Zumla A, Raviglione M. The global tuberculosis epidemic and progress in care, prevention, and research: an overview in year 3 of the End TB era. Lancet Respir Med 2018; 6: 299-314.

3. Houben RM, Dodd PJ. The global burden of latent tuberculosis infection: a re-estimation using mathematical modelling. PLoS Med 2016; 13: e1002152.

4. Khan MK, Islam MN, Ferdous J, Alam MM. An overview on epidemiology of tuberculosis. Mymensingh Med J 2019; 28: 25966.

5. Solante MB, Chagan-Yasutan H, Hattori T, Leano S, Garfin AMCG, Soolingen DV, et al. High rates of human immunodeficiency virus and drug resistance in tuberculosis patients in Manila, Philippines. Biomed Biotechnol Res J 2017; 1: 157-62.

6. Nair D, Velayutham B, Kannan T, Tripathy JP, Harries AD, Natrajan $\mathrm{M}$, et al. Predictors of unfavourable treatment outcome in patients with multidrug-resistant tuberculosis in India. Public Health Action 2017; 7: 32-8.

7. Piergallini TJ, Turner J. Tuberculosis in the elderly: why inflammation matters. Exp Gerontol 2018; 105: 32-9.
8. Hanson C, Osberg M, Brown J, Durham G, Chin DP. Finding the missing patients with tuberculosis: lessons learned from patientpathway analyses in 5 countries. J Infect Dis 2017; 216(suppl_7): S686-S695.

9. Sharma P, Lalwani J, Pandey P, Thakur A. Factors associated with the development of secondary multidrug-resistant tuberculosis. Int J Prev Med 2019; 10: 67.

10. Al-Orainey IO. Drug resistance in tuberculosis. J Chemother 1990; 2: $147-51$.

11. Alipanah N, Jarlsberg L, Miller C, Linh NN, Falzon D, Jaramillo $\mathrm{E}$, et al. Adherence interventions and outcomes of tuberculosis treatment: a systematic review and meta-analysis of trials and observational studies. PLoS Med 2018; 15: e1002595.

12. Yasri $\mathrm{S}$, Wiwanitkit $\mathrm{V}$. Knowledge on tuberculosis in rural Myanmar. Int J Mycobacteriol 2017; 6: 412-3.

13. Zhang CY, Zhao F, Xia YY, Yu Y-L, Shen X, Lu W, et al. Prevalence and risk factors of active pulmonary tuberculosis among elderly people in China: a population based cross-sectional study. Infect Dis Poverty 2019; 8: 7.

14. Yoshikawa TT, Marrie TJ. Community-acquired pneumonia in the elderly. Clin Infect Dis 2000; 31: 1066-78. 